\title{
Estimation of Effective Wave Slope Coefficient of Ships with Large Breadth and Draught Ratio
}

\author{
Daeng Paroka ${ }^{1)^{*}}$, Andi Haris Muhammad ${ }^{2}$, Sabaruddin Rahman ${ }^{1)}$ \\ 1) Department of Ocean Engineering, Hasannudin University, Gowa 92119, Indonesia \\ 2) Department of Marine System Engineering, Hasannudin University, Gowa 92119, Indonesia \\ *) Corresponding Author : dparoka@eng.unhas.ac.id
}

\section{Article Info}

Keywords:

Ship Stability,

Weather Criteria,

Wave Slope Coefficient,

Ro-Ro Ferry

\section{Article history:}

Received: 02/02/20

Last revised: $26 / 02 / 20$

Accepted: 26/02/20

Available online: 29/02/20

DOI:

https://doi.org/10.14710/kapal. v17i1.28399

\section{Abstract}

One of the parameters to estimate heel angle of a ship in beam seas is an effective wave slope coefficient. In the weather criterion of IMO, the effective wave slope coefficient is determined as a function of ratio between distance of center of gravity from the sea surface and the ship draught. The other methods that could be used to estimate the effective wave slope coefficient are simplified strip theory and model experiment. A ship with a shallow draught and large vertical center of gravity can have an effective wave slope coefficient larger than 1.0 if the coefficient is calculated by using the formulae of weather criterion. Therefore, an alternative method to estimate the coefficient is necessary when it is applied to ships with geometry characteristics different from those used to develop the formulae. This research conducts to estimate the effective wave slope coefficient using three different methods, namely the formulae of weather criterion, the simplified strip theory and model experiment. The results of the three methods may provide enough evidence about a suitable method to estimate the effective wave slope coefficient of ships with breadth and draught ratio larger than 3.5, like the Indonesian ro-ro ferries. Results and discussion show that the effective wave slope coefficient obtained by using the formulae of weather criterion is larger compared to that obtained by using the simplified strip theory and the model experiment. Here, the result of simplified strip theory for wave frequency the same as the natural roll frequency of subject ship is similar to the result of model experiment. These results show that the simplified strip theory can be used as an alternative method to determine the effective wave slope of a ship with breadth and draught ratio larger than 3.5 if the results of model experiment are not available.

Copyright (c) 2020 KAPAL : Jurnal Ilmu Pengetahuan dan Teknologi Kelautan. This is an open access article under the CC BY-SA license (https://creativecommons.org/licenses/by-sa/4.0/).

\section{Introduction}

One of the essential variables for ship stability evaluation using the criteria of the International Maritime Organization (IMO), especially the weather criterion [1], This coefficient is a correction factor that corresponds to the roll excitation moment induced by waves. The weather criterion of IMO uses an empirical formula to calculate the effective wave slope coefficient as function of ratio between the vertical center of gravity and the ship draught. These formulae were statistically developed based on ships with breadth and draught ratio smaller than 3.50 , the block coefficient smaller than 0.70 and the ratio between the vertical center of gravity and the ship draught between 0.70 and 1.50 [1]. Some researchers found that the result of the formulae is overestimated when it is applied to a ship with different characteristics geometry such as large passenger ships, ropax ships and ro-ro ferries [2], [3], [4]. The effective wave slope coefficient should not be larger than 1.0, therefore Fancescutto [5] recommends that this coefficient is 1.0 when the result of the formulae is larger than 1.0.

The effective wave slope coefficient becomes more crucial following the finalization of the second generation intact stability criteria (SGISC), where the ship stability will be evaluated based on operational performance in seaways [6]. In cases of a ship operates in beam seas, the prediction method of wind and wave excitation moments has a significant effect on vulnerability criteria level 1 and vulnerability criteria level 2 of the SGISC for dead ship condition. The wave excitation moment for roll motion is a function of geometry characteristics and it can empirically be estimated if the data of effective wave slope coefficient is available. Therefore, the accuracy of safety level calculation in the SGISC significantly depends on the accuracy of the effective wave slope coefficient

Several methods to estimate the effective wave slope coefficient have been developed, such as strip theory, computational fluid dynamics (CFD) as well as a model experiment [7]. For implementation of the SGISC, IMO recommended 
experimental procedure as an alternative method to evaluate the weather criterion (vulnerability criteria level 1 for dead ship condition in the SGISC) mainly for ships with geometry characteristics different from those used to develop the criterion [8]. For practical purposes, an empirical formulae such as the formulae in the weather criterion of IMO is a simpler one to use compared to the numerical method as well as a model experiment. Still, the result of the formulae tends to be overestimated when it is applied to a ship with breadth and draught ratio larger than 3.50 [4].

This paper discusses the effective wave slope coefficient estimated with three different methods, namely empirical formulae of weather criterion, simplified strip theory with the assumption of Froude-Krylov excitation force and moment [9] as well as model experiment that following the recommended procedure of IMO [8]. Those three methods seem to be simpler compared to the numerical method. The purpose of this study is to investigate the possibility of using a simpler method to estimate the effective wave slope coefficient of ships with geometry characteristics different with those are used to develop the weather criterion such as the Indonesian ro-ro ferries, inland ships and river-seas ship [7]. This issue is essential relating to the implementation of the SGISC to the ships in the future, both in the design step and operational safety. The results may also be used as a reference to extend the semi-empirical formulae of effective wave slope coefficient prediction applied to ships with breadth and draught ratio larger than 3.50.

\section{Methods}

An Indonesian ro-ro ferry is used as a sample ship in this research. The principles dimension and the body plan of the ship are shown in Table 1 and Figure 1, respectively. The ship has a ratio between breadth and draught of 5.18 with freeboard and breadth ratio of 0.08 . Most of Indonesian ro-ro ferries, especially which are built in Indonesian shipyards have breadth and draught ratio larger than 3.50 and the ratio between freboard and breadth smaller than 0.10 as shown in Figure 2 and Figure 3, respectively. In order to comply with the general criteria of intact stability code, Paroka [10] recommended ratio between freeboard and breadth larger than 0.10 . Ratio between vertical center of gravity and the draught of the subject ship is 1.75 larger than the maximum ratio used to develop the weather criterion. The Indonesian ro-ro ferries were designed with small draught considering the water depth of port. In order to fulfill the capacity requirement, the ship is designed with large breadth. The low freeboard is meant to easily load and unload the vehicles from the car deck, especially in the port with large tidal without mobile bridge facility.

Table 1. Principles Dimension

\begin{tabular}{ll}
\hline Parameter & Value (m) \\
\hline Length between perpendiculars (Lbp) & 50.50 \\
Breadth (B) & 14.00 \\
Height (H) & 3.80 \\
Draught (d) & 2.70 \\
Vertical center of gravity (KG) & 4.72 \\
Block coefficient & 0.70 \\
\hline
\end{tabular}

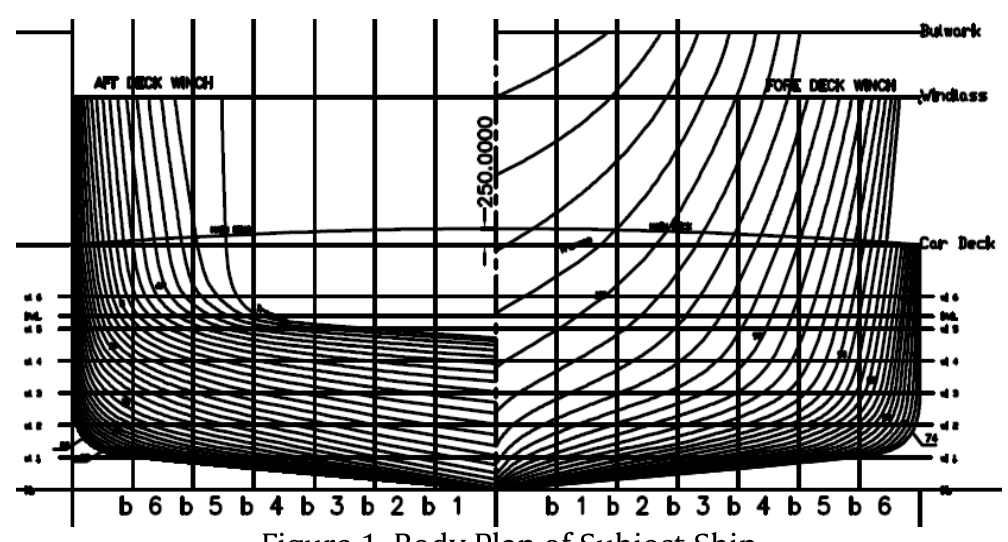

Figure 1. Body Plan of Subject Ship 


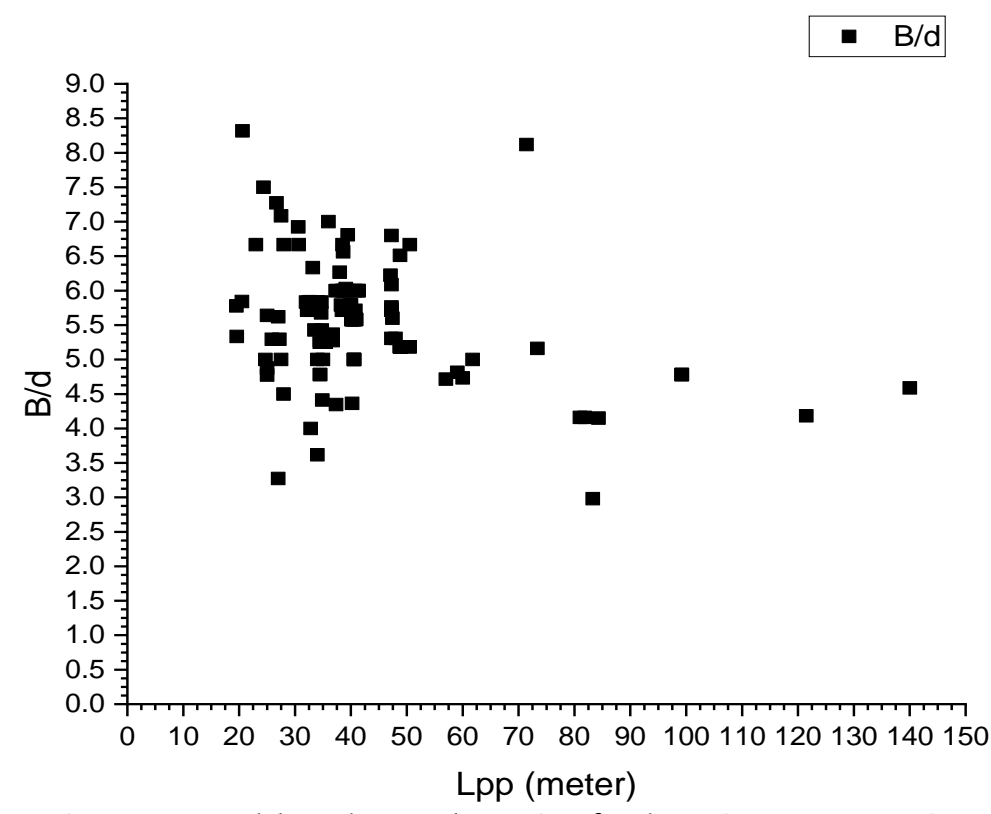

Figure 2. Breadth and Draught Ratio of Indonesian Ro-Ro Ferries

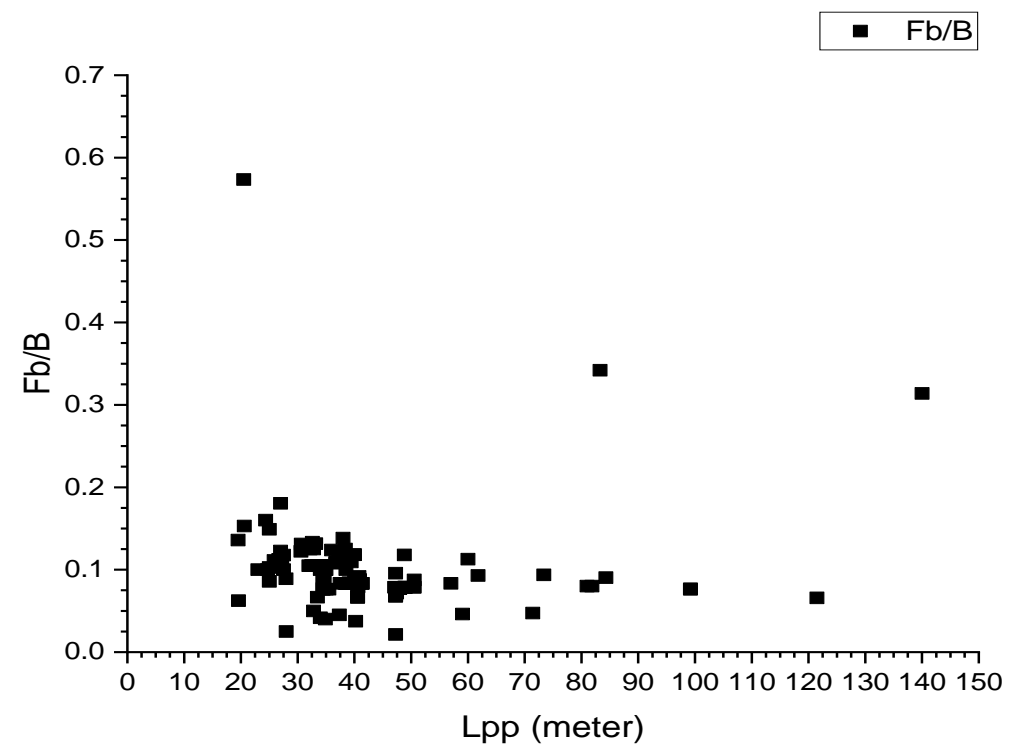

Figure 3. Ratio between Freeboard and Breadth of Indonesian Ro-Ro Ferries

\subsection{Weather Criterion}

The formulae to calculate the effective wave slope coefficient based on the weather criterion of IMO is written as the equation as follows [1]:

$$
r=0.70+0.63 \frac{O G}{d}
$$

Here, $O G$ indicates the distance of center of gravity from the water surface. Value of $O G$ is positive if the center of gravity is located above the water surface. Otherwise its value is negative.

Based on the Eq. 1, a ship with small draught compared to vertical center of gravity may have a larger effective wave slope coefficient, which is an overestimate one because that coefficient should be smaller than 1.0 [5]. Oppositely, a ship with large draught may have an underestimate coefficient because a smaller ratio between vertical center of gravity and ship draught.

Figure 4 shows the effective wave slope coefficient of the subject ship for variation of the ratio between the distance of vertical center of gravity from the water surface and the draught. This coefficient is calculated in wave frequency the same as the natural frequency of roll in which the largest roll motion in beam seas occurs. Following the Eq. 1, ships with the same ratio between the vertical center of gravity and draught will have the same effective wave slope coefficient. 


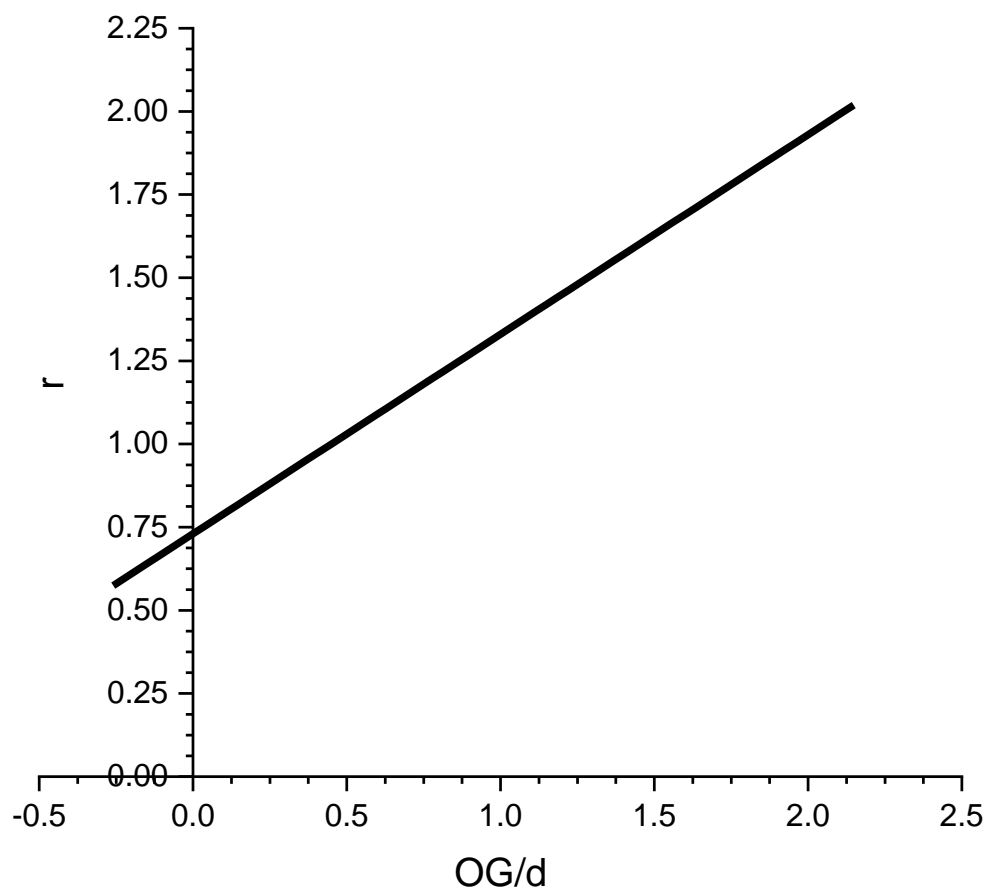

Figure 4. Effective Wave Slope Coefficient as a Function of Ratio Between the Distance of Center of Gravity Form Sea Surface and Ship Draught

\subsection{Simplified Strip Theory}

In this method, the wave-exciting moment of roll motion considers only the Froude-Krylov part, which is based on the fact that the diffraction moment in roll cancels out the radiation moment due to sway in roll when the wavelength is much larger than the ship breadth [11]. To calculate the Foude-Krylov moment, the ship hull is divided into several cross-sections. The wave-exciting moment acting on ship hull is calculated by integrating the moment induced by the wave in each crosssection. The effective wave slope coefficient is then calculated for a certain wave frequency using the Eq. 2 [9].

$$
r(\omega)=\left|\frac{\int_{L} C(x) d x}{\nabla_{e q} \cdot G M_{T_{e q}}}\right|
$$

Where

$$
\begin{gathered}
C(x)=\left\{\begin{array}{c}
0 \text { if } A_{e q}(x)=0 \text { and } B_{e q}(x)=0 \\
A_{e q}(x) \cdot\left[K_{1}(x)+K_{2}(x)+F_{1}(x) \cdot O G\right]
\end{array}\right. \\
r K_{1}(x)=G(x) \cdot \frac{\left(1+k_{w} \cdot T_{e q}(x)\right) \cdot e^{-k_{w} \cdot T_{e q}(x)}-1}{k_{w}{ }^{2} \cdot T} \\
K_{2}(x)=-\frac{e^{-k_{w} \cdot T_{e q}(x)}}{k_{w}{ }^{2} \cdot T_{e q}(x)} \cdot\left[\cos \left(k_{w} \cdot \frac{B_{e q}(x)}{2}\right)-G(x)\right] \\
F_{1}(x)=-\frac{1-e^{-k_{w} \cdot T_{e q}(x)}}{k_{w} \cdot T_{e q}(x)} \cdot G(x) \\
G(x)=\frac{\sin \left(k_{w} \cdot \frac{B_{e q}(x)}{2}\right)}{\left(\frac{k_{w} \cdot B_{e q}(x)}{2}\right)}
\end{gathered}
$$

The equivalent volume $\left(\nabla_{e q}\right)$ dan the equivalent metacentric height $\left(G M_{T_{e q}}\right)$ are calculated with assumption that the cross-sections have rectangular form by keeping its area the same as the area of the original cross-section. The simplification of the cross-section form to be a rectangular one with equivalent breadth of $B_{e q}(x)$ and the equivalent draught of $T_{e q}(x)$ is conducted with the following approximation. 


$$
\begin{gathered}
\text { if } \frac{A(x)}{B(x)} \leq T(x) \text { then }\left\{\begin{array}{l}
A_{e q}(x)=A(x) \\
B_{e q}(x)=B(x) \\
T_{e q}(x)=\frac{A(x)}{B(x)}
\end{array}\right. \\
\text { if } \frac{A(x)}{B(x)}>T(x) \text { then }\left\{\begin{array}{c}
T_{e q}(x)=T(x) \\
B_{e q}(x)=B(x) \\
A_{e q}(x)=B_{e q}(x) \cdot T_{e q}(x)
\end{array}\right.
\end{gathered}
$$

The equivalent volume and the equivalent metric height using the obtained equivalent breadth and equivalent draught are calculated by using the following equation:

$$
\begin{gathered}
\nabla_{e q}=\int_{L} A_{e q}(x) d x \\
G M_{T_{e q}}=B M_{T_{e q}}+K B_{e q}-K G
\end{gathered}
$$

Here, the equivalent transverse metacentric radius as well as the equivalent vertical center of buoyancy are calculated by using the equation as follow:

$$
\begin{gathered}
B M_{T_{e q}}=\frac{1}{\nabla_{e q}} \cdot \int_{L} \frac{1}{12} \cdot B_{e q}{ }^{3}(x) d x \\
r K B_{e q}=T+\frac{1}{\nabla_{e q}} \int_{L} \frac{-T_{e q}(x)}{2} \cdot A_{e q}(x) d x
\end{gathered}
$$

The Eq. 2 shows that the effective wave slope coefficient is a function of wave frequency. The effect of wave frequency in this method can be seen in the Eq. 4 to the Eq. 6 in which the coefficients $K_{1}(x), K_{2}(x)$ and $F_{1}(x)$ are function of wave number, $k_{w}$. The wave number itself is function of wave frequency or wave length.

In order to compare the effective wave slope coeffient obtained by the formulae of weather criterion, this method is also used to calculate that coefficient for the wave frequency the same as the natural frequency of roll motion. The obtained results are also function of the ratio between the distance of vertical center of gravity from the water surface and the ship draught. It can be seen in the Eq. 3 that this ratio has a significant effect on the Froude-Krylov exciting moment.

\subsection{Model Model Experiment}

In order to calculate the effective wave slope coefficient by model experiment, two model experiments should be conducted, namely the roll decay test and the drift test in beam seas [8]. The roll decay test is performed to determine the linear and nonlinear damping coefficients as well as the natural roll period. Those damping coefficients are obtained following the method recommended by International Towing Tank Conference (ITTC) [12]. The Bertin's coefficient is then calculated by using the following equation:

$$
N\left(\phi_{m_{i}}\right)=\frac{a}{\phi_{m_{i}}}+b
$$

where $a$ and $b$ are the linear and the nonlinear coefficients of polynomial equation of decay amplitude of roll as function of average two consecutive roll amplitude of roll decay test results. The effective wave slope coefficient is calculated by using the equation as follows [8]:

$$
r r=\frac{\phi_{1_{r}}^{2} \cdot N\left(\phi_{1_{r}}\right)}{90 . \pi \cdot s}
$$

Here, $\phi_{1_{r}}$ is the maximum roll angle obtained by drift test in regular beam seas with wave steepness, $s$. The drift test is conducted for several different wave slope with wave frequency of 0.8 to 1.2 of the natural frequency of roll. The effective wave slope coefficient is then statistically determined based on the obtained coefficients for each wave steepness.

Those two model experiments should be performed with model scale larger than $1: 40$ or the model length to be 2.0 meters or longer which one is larger. The weight distribution on the model should be similar with weight distribution in the real ship. This weight distribution corresponds to the center of gravity and the roll radius gyration which has significant effect on the natural roll period. The weight distribution for the present experiment is determined following the loading plan $\mathrm{f}$ the subject ship mainly on the vehicles deck. That loading plan corresponds to the " $\mathrm{C}$ " coefficient of 0.35 smaller that that obtained by the formulae in the weather criterion. The formulae may induce significant error when it is applied to a ship with large breadth and draught ratio as well as large metacentric height [13]. 


\section{Results and Discussion}

The effective wave slope coefficient obtained by using the formulae of the IMO weather criterion, as shown in the Eq. 1 can be seen in Figure 5. This coefficient becomes larger than 1.0 when the vertical center of gravity is larger than 1.48 of the ship draught. The sample ship with a draught of 2.7 meters as shown in the Table 1, the effective wave slope coefficient larger than 1.0 occurs when the vertical center of gravity is 3.99 meters or larger. This vertical center of gravity is smaller than the vertical center of gravity of the subject ship of 4.72 meters in full loading condition.

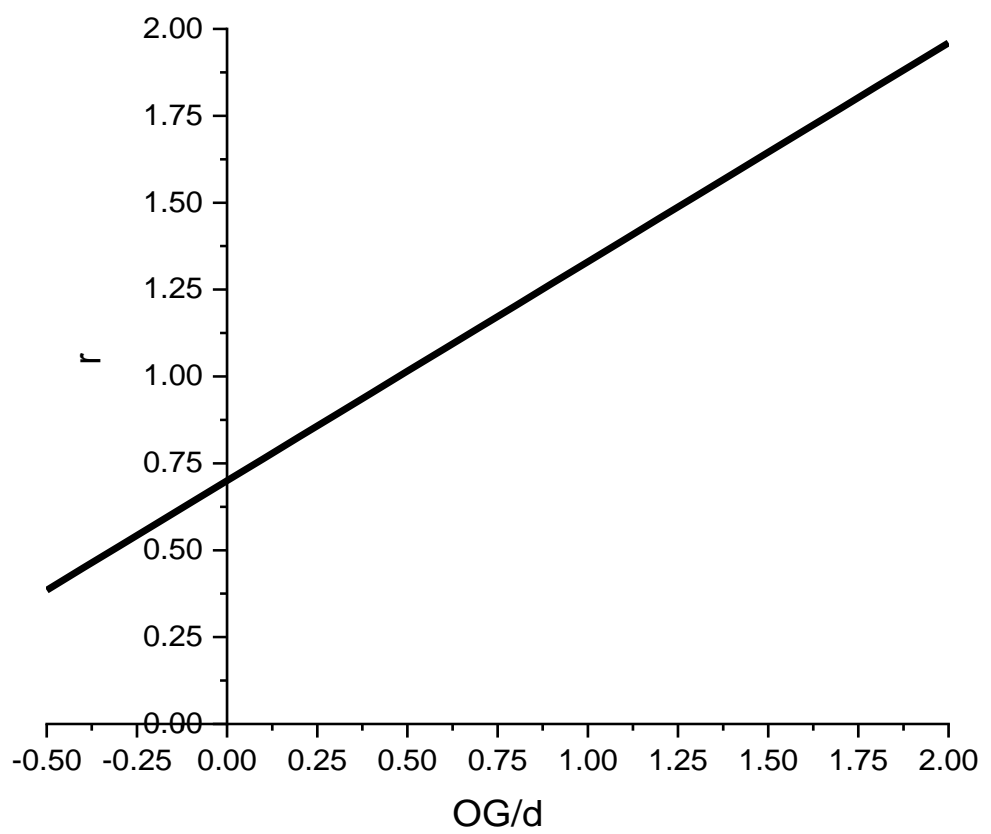

Figure 5. Effective Wave Slope Coefficient Based on the Formulae of IMO Weather Criterion [1]

The results of some researches show that the effective wave slope coefficient should not be larger than 1.0. If the obtained results of the Eq. 1 are larger than 1.0 then the effective wave slope coefficient used to calculate the roll-back angle in the weather criterion is taken to be 1.0 [5]. Nevertheless, results of some researches show that for certain types of ships, especially large passenger ships and ro-pax, the effective wave slope coefficient obtained by using the formulae of weather criterion is larger than that obtained by model experiment [2], [3], [14]. This means that the roll-back angle obtained by using the effective wave slope coefficient based on the formulae of weather criterion will be larger than that obtained by using the effective wave slope coefficient based on model experiment. Therefore, IMO recommends using the model experiment for evaluation of the weather criterion for ships with geometry characteristics different with those are used to develop the criterion.

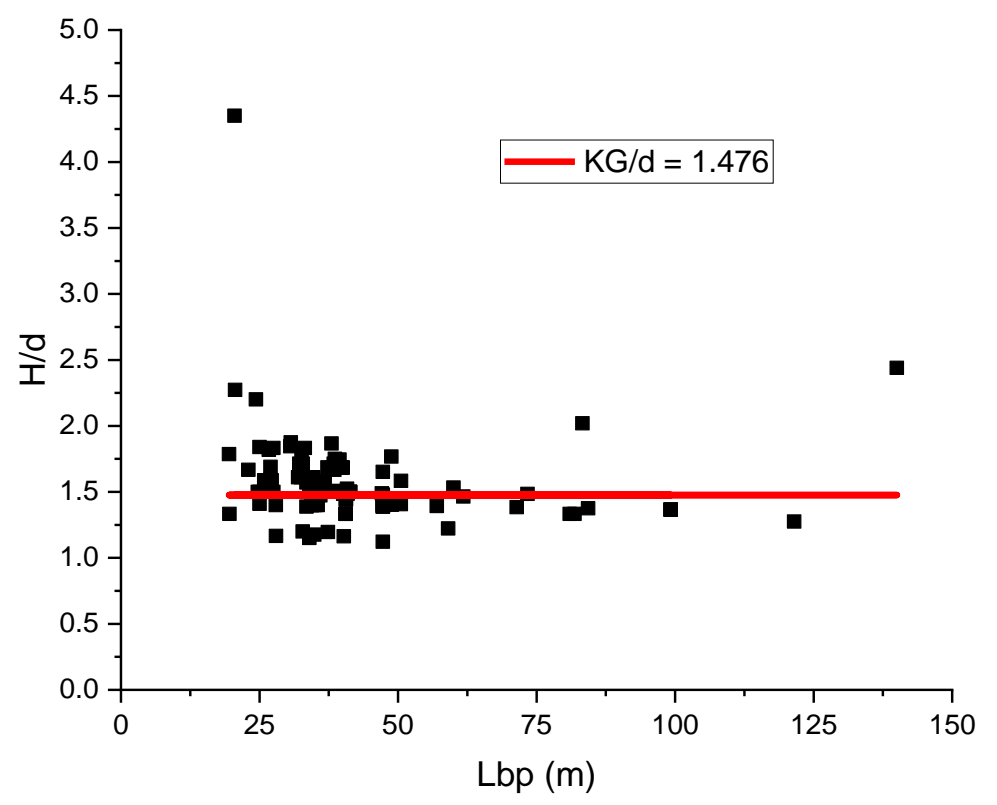

Figure 6. Ratio between Height and Draught of Indonesian Ro-Ro Ferries 
If the vertical center of gravity is assumed to be larger than the ship height (as the sample ship used in this paper), it can also be assumed that the effective wave slope coefficient that calculated by using the formulae of weather criterion will be larger than 1.0 if the rasio between the ship height and the ship draught is larger than 1.48. Most of Indonesian ro-ro ferries have height and draught ratio larger than 1.48 as shown in Figure 6. This means that stability assessment for Indonesian ro-ro ferries using the weather criterion with the effective wave slope coefficient obtained by the formulae of weather criterion results in an overestimates safety level compared to that by using the effective wave slope coefficient based on a model experiment. As result, the minimum metacentric height complies with the weather criterion becomes larger. Therefore, an alternative method to estimate the effective wave slope coefficient is important regarding application of the weather criterion into stability evaluation of the Indonesian ro-ro ferries.

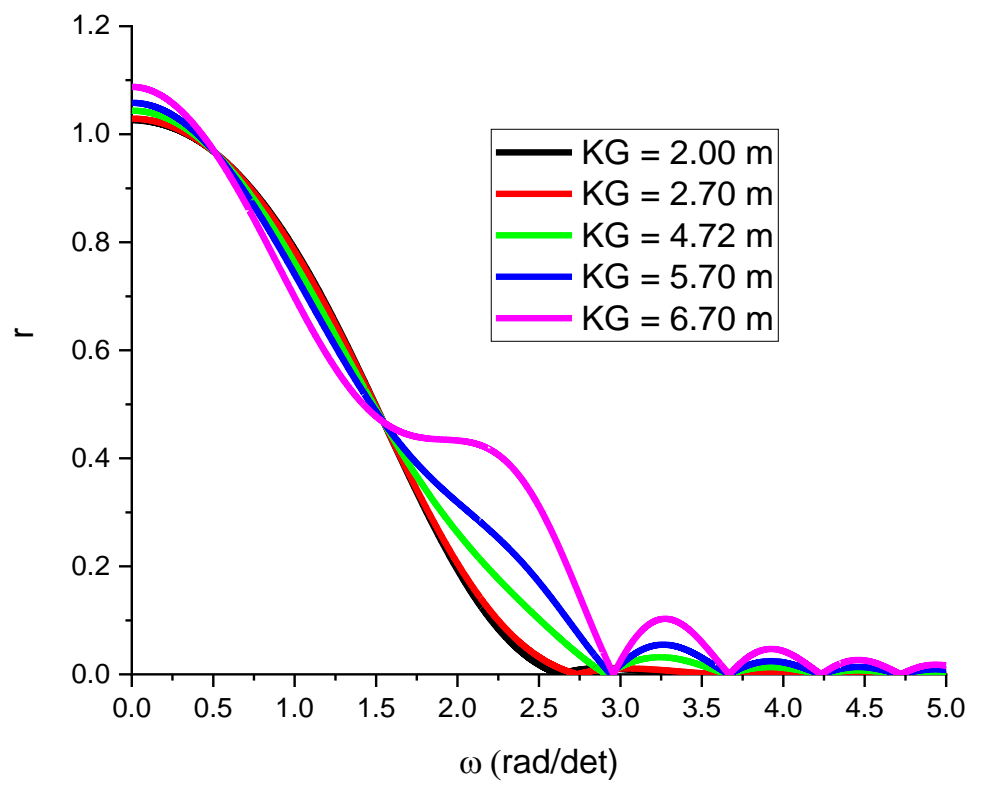

Figure 7. Effective Wave Slope Coefficient Obtained by Simplified Strip

The effective wave slope coefficient obtained the simplified strip theory method for five different vertical center of gravities are shown in Figure 7. The calculation is conducted for full loading condition for all variations of vertical center of gravity. The effective wave slope coefficient becomes smaller due to increase the wave frequency. In cases of lower wave frequency or larger wave length, the effective wave slope coefficient does not significantly change due to alteration of the vertical center of gravity. That coefficient value is 1.03 for vertical center of gravity of 2.0 meters and that is 1.09 for vertical center of gravity of 6.7 meters. The effective wave slope coefficient tends to decrease due to the increase in vertical center of gravity in the wave frequency range from $0.513 \mathrm{rad} / \mathrm{s}$ to $1.547 \mathrm{rad} / \mathrm{s}$. However, this coefficient increases with the vertical center of gravity when the wave frequency is larger than $1.547 \mathrm{rad} / \mathrm{s}$. A very small effective wave slope coefficient is obtained in the wave frequency larger than $3.0 \mathrm{rad} / \mathrm{s}$. The wavelength corresponds to the wave frequency of $3.0 \mathrm{rad} / \mathrm{s}$ is $6.85 \mathrm{~meters}$ smaller than a half of the ship breadth. Bulian, et al [15] shows that this coefficient can be neglected when the wavelength is smaller than a half of ship breadth.

Figure 8 shows the effective wave slope coefficient as a function of ratio between vertical distance of center of gravity from the sea surface and the ship draught. Those coefficients are calculated in the wave frequency the same the natural frequency of roll. This natural frequency changes with variation of vertical center of gravity. The effective wave slope coefficient increases when the ratio between vertical distance of center of gravity from the sea surface and the ship draught increases. However, this coefficient decreases due to increase the vertical center of gravity when that ratio larger than 1.50 . The effective wave slope coefficient for the vertical center of gravity located in the sea surface is 0.38 smaller than that in the formulae of weather criterion of 0.70 . Alteration coefficient of effective wave slope coefficient due to variation of vertical center of gravity is 0.21 when the calculation is conducted by simplified strip theory and that is 0.63 when the calculation is performed by the formulae of weather criterion. In the full loading condition with vertical center of gravity shown in Table 1 , the effective wave slope coefficient obtained by the simplified strip theory is 0.54 smaller than that obtained by the formula of weather criterion of 1.17 .

Results of model experiments for four different wave characteristic is shown in Figure 9. The effective wave slope coefficient does not significantly different for different wave steepness. Bulian, et al [15] proposed that the effective wave slope coefficient is independent of the wave frequency, but it is the same as zero when the wavelength is smaller than half of ship breadth. This assumption can be used to assess ship stability based on the weather criterion but for calculating capsizing index as parameter of safety level in seaways, IMO recommends the simplified strip theory to obtain the effective wave slope coefficient as function of wave frequency. 


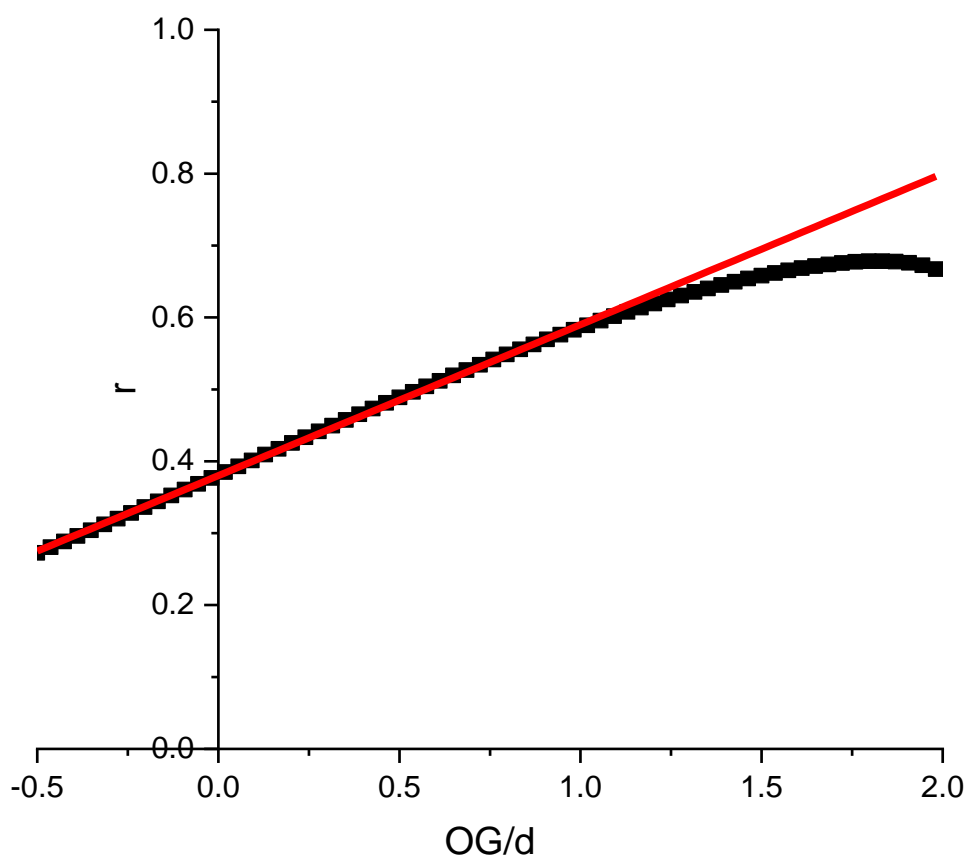

Figure 8. Effective Wave Slope Coefficient Obtained by Simplified Strip Theory in The Natural Frequency Of Roll

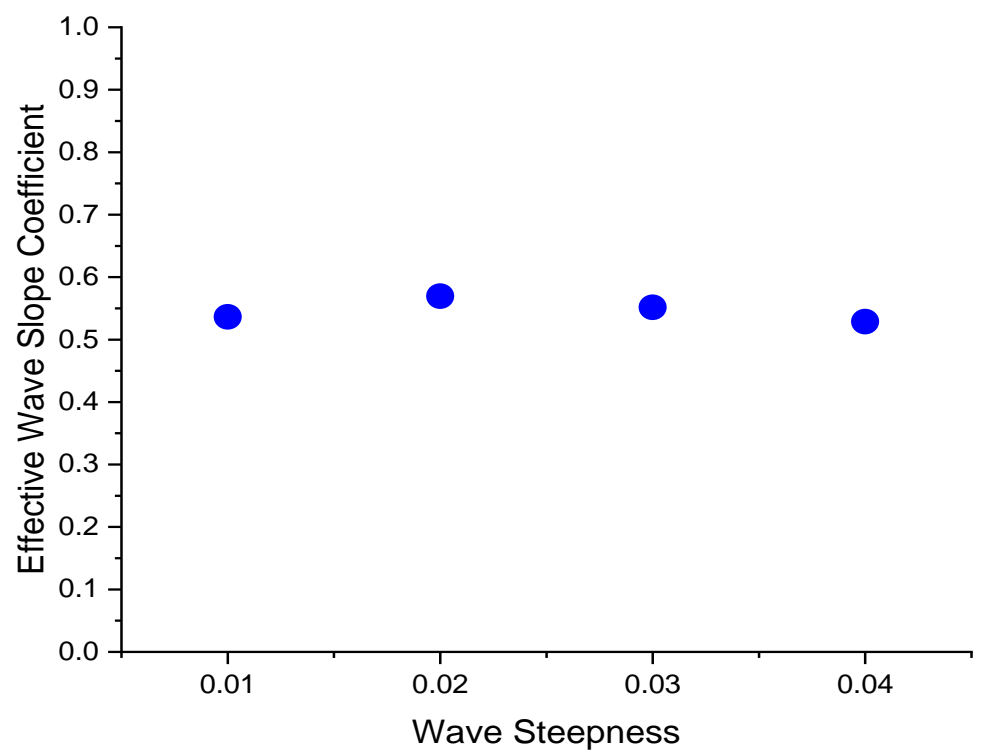

Figure 9. Effective wave slope coefficient obtained by model experiment [14]

The effective wave slope coefficient obtained by model experiment is similar to that obtained by the simplified strip theory. However, results of these two methods are smaller than the result of the formulae of weather criterion. Sato, et al [4] also obtained a similar result between the model experiment and the simplified strip theory for an offshore supply vessel which are also smaller than the result of the formulae of weather criterion. This different results show that the formulae of weather criterion result in an overestimate effective wave slope coefficient when it is applied to a ship breadth and draught ratio larger than 3.50 with the ratio between the distance of center of gravity from the sea surface and the ship draught out of the range used to develop the formulae. Therefore, the accuracy of calculation result obtained by the weather criterion formulae should be verified by result of model experiment when the weather criterion is applied to a ship with geometry characteristics different with those used to develop the criterion. These results also show that the simplified strip theory could be used to estimate the effective wave slope coefficient of ships with small draught with the ratio between the breadth and the draught larger than 3.5 and the ratio between vertical center of gravity and the draught larger than 1.50 if data from model experiment does not available.

Figure 10 shows results of stability evaluation using the weather criterion with effective wave slope coefficient calculated by using the three methods. The minimum metacentric height comply with the weather criterion is 3.9 meters when the effective wave slope coefficient is calculated by using the formulae of weather criterion. This minimum metacentric height is larger than that obtained by using the simplified strip theory of 2.0 meters. The minimum metacentric height of the subject ship when the effective wave slope coefficient determined by model experiment is 1.8 meters. Those three minimum metacentric height are still smaller than the metacentric height of the subject ship in full loading condition. These results show that the simplified strip theory can be used as an alternative method to determined the effective wave slope coefficient 
of ship with large breadth and draught ratio such as the Indonesian ro-ro ferries when the result of model experiment are not available.

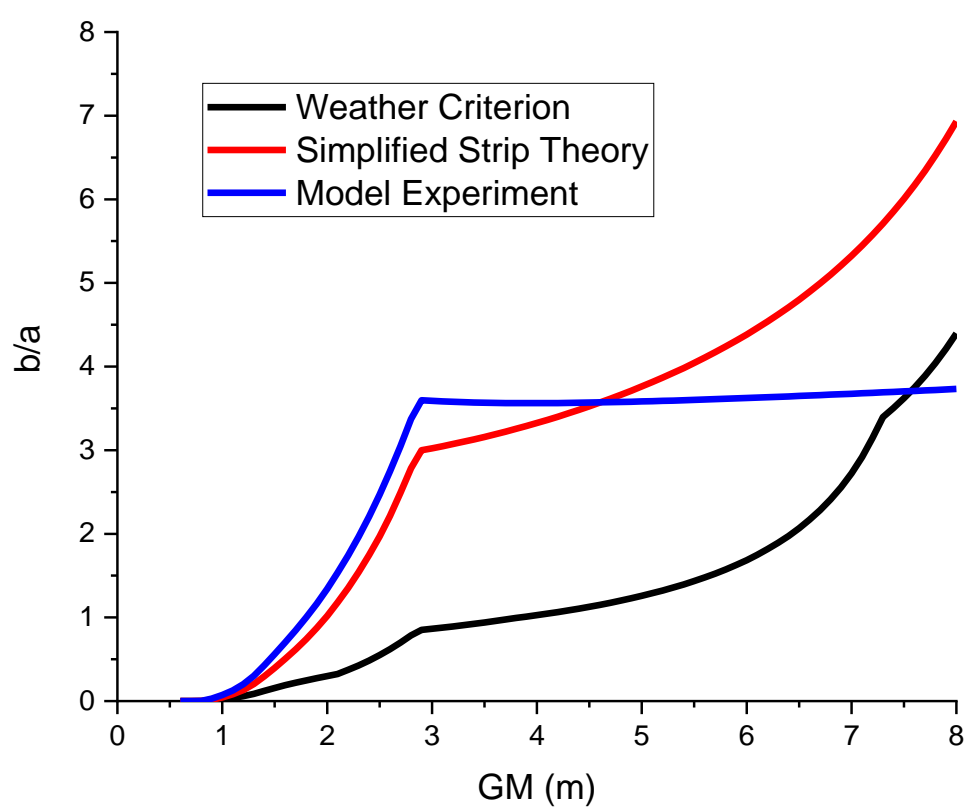

Figure 10. b/a coefficient of weather criterion for three different metode to estimate the effective wave slope coefficient

\section{Conclusion}

Estimation of effective wave slope coefficient for an Indonesian ro-ro ferry with main particulars shown in Table 1 has been conducted by using three different methods, namely the formulae of weather criterion, the simplified strip theory with Froude-Krylov wave exciting moment as well as model experiment. The obtained results are then used to calculate the minimum metacentric height of the subject ship to comply with the weather criterion of IMO. Based on results and discussion, it can be concluded that the effective wave slope coefficient obtained by the simplified strip theory does not look significantly different from that obtained by model experiments. The results of those two methods are smaller than those obtained by the formulae of weather criterion.

The minimum metacentric height complies with the weather criterion is 3.8 meters when the effective wave slope coefficient is calculated by using the formulae of weather criterion. If the effective wave slope coefficient is calculated by using the simplified strip theory, the minimum metacentric height complies with the weather criterion is 2.0 meters and that is 1.80 meters when the effective wave slope coefficient is determined by using model experiment. These minimum metacentric heights indicate that the subject ship complies with the weather criterion when the effective wave slope coefficient is estimated by using the present three methods. The simplified strip theory can be used as an alternative method to determine the effective wave slope coefficient of ships with large breadth and draught ratio, such as the Indonesian ro-ro ferries, if experimental results are not available.

\section{Acknowledgements}

The data presented in this paper is a part of results of research supported by Directorate General of Higher Education and Hasanuddin University with grant number of 4907/UN4.21/PT.01.09/2019. The authors express their sincere gratitude and appreciation to those institutions for their support.

\section{References}

[1] I. M. O. Resolution, "267 (85)-adoption of the international code on intact stability." London, UK: IMO Publishing, 2008.

[2] A. Francescutto, A. Serra, and S. Scarpa, "A critical analysis of weather criterion for intact stability of large passenger vessels," in OMAE 2001, 2001, pp. 1-8.

[3] S. Ishida, H. Taguchi, and H. Sawada, "Evaluation of the Weather Criterion by Experiments and its Effect to the Design of a RoPax Ferry," in Contemporary Ideas on Ship Stability and Capsizing in Waves, Springer, 2011, pp. 65-78.

[4] Y. Sato, H. Taguchi, M. Ueno, and H. Sawada, "An experimental study of effective wave slope coefficient for twodimensional model," in 6th Osaka Colloquium on Seakeeping and Stability of Ships (OC2008), 2008.

[5] A. Francescutto, "Intact stability criteria of ships--Past, present and future," Ocean engineering, vol. 120, pp. 312-317, 2016.

[6] IMO, "Finalization of Second Generation Intact Stability Criteria: Information Collected by the Correspondence Group on Intact Stability Regarding Second Generation Intact Stability Criteria," in Document SDC 3/INF.10 Submitted by Japan, 2015. 
[7] S. Rudaković, G. Bulian, and I. Bačkalov, "Effective wave slope coefficient of river-sea ships," Ocean Engineering, vol. 192, p. 106427, 2019.

[8] IMO, "Interim Guidelines for Alternative Assessment of Weather Criterion," in Document MSC.1/Circ.1200, 2006.

[9] IMO, "Development of Second-Generation Intact Stability Crtieria: Vulnerability Assessment for Dead-Ship Stability Failure Mode," in Document SDC 1/INF.6 Submitted by Italy and Japan, 2013.

[10] D. Paroka, "Karakteristik geometri dan pengaruhnya terhadap stabilitas kapal ferry ro-ro Indonesia," Kapal: Jurnal Ilmu Pengetahuan dan Teknologi Kelautan, vol. 15, no. 1, pp. 1-8, 2018.

[11] F. Tasai and M. Takagi, "Theory and Calculation Method for Response in Regular Waves (in Japanese)," in The Seakeeping Symposium, Society of Naval Architects of Japan, 1969.

[12] ITTC, "Numerical Estimation of Roll Damping: Recommended Procedures," in The 26th ITTC Specialist Committee on Stability in Waves, 2011.

[13] R. Borisov, A. Luzyanin, M. Kuteynikov, and V. Samoylov, "An approach to assess the excessive acceleration based on defining roll amplitude by Weather Criterion formula with modified applicability range," Proceedings of STAB, pp. 601-612, 2015.

[14] D. Paroka, S. A. Rosmani, and Hamzah, "Alternative Assessment of Weather Criterion for Ships with Large Breadth and Draught Ratios by Model Experiment: A Case Study on an Indonesian Ro-Ro Ferry," International Journal of Maritime Engineering, 2019.

[15] G. Bulian and A. Francescutto, "A simplified modular approach for the prediction of the roll motion due to the combined action of wind and waves," Proceedings of the Institution of Mechanical Engineers, Part M: Journal of Engineering for the Maritime Environment, vol. 218, no. 3, pp. 189-212, 2004. 